\title{
ANÁLISE QUANTITATIVA DE MASTÓCITOS E DE GRANULÓCITOS EOSINÓFILOS NO MIOCÁRDIO DE RATOS WISTAR CRONICAMENTE INFECTADOS PELO TRYPANOSOMA CRUZI. CONTRIBUIÇÃO AO CONHECIMENTO DA FIBROSE MIOCÁRDIA
}

\author{
Maria da Conceição Nascimento Pinheiro, Paulo Sérgio Siebra Beraldo, Luiz \\ Fernando Junqueira Júnior, Edison Reis Lopes e Edmundo Chapadeiro
}

\begin{abstract}
Foi feito o estudo quantitativo de mastócitos e de granulócitos eosinófilos no miocárdio de 40 ratos albinos Wistar. Trinta animais encontravam-se na fase tardia da infecção ( $8^{\circ} \cdot$ mês) produzida pelas cepas São Felipe, Y e Colombiana do Trypanosoma cruzi, e apresentavam graus variáveis de miocardite crônica; 10 ratos serviram como controles. Miocardite crônica fibrosante (fibrose) ocorreu em $40 \%$ dos animais infectados e detectou-se aumento do número de mastócitos nos animais. chagásicos, o qual se associou à infecção mas não à fibrose miocárdica. Não se constatou aumento do número de eosinófilos.
\end{abstract}

\section{Palavras-chaves: Doença de Chagas. Fibrose miocárdica. Mastócitos. Granulocitos eosinófilos.}

Tem-se atribuído à fibrose miocárdica papel importante na insuficiência cardíaca da doença de Chagas, a qual resultaria de uma contínua produção de colágeno no foco inflamatório ${ }^{4} 9$. De modo similar admitem alguns ${ }^{9} 25$ que a fibrose das musculares próprias do tubo digestivo poderia ser também um dos fatores patogenéticos do megaesôfago e do megacólon observados na mesma doença.

Na tripanosomíase cruzi, humana e experimental, tanto no coração comó no esôfago, tem sido relatado aumento do número de mastócitos, ligado ou não ao processo inflamatório ${ }^{12} 12212325$. Quanto à participação dos eosinófilos, embora não existindo estudos quantitativos, trabalhos identificam sua presença tanto no coração como no esôfago de chagásicos crônicos ${ }^{1810111314151617}$ 21222425 .

Constata-se, portanto, não estar clara a participação dos mastócitos e dos eosinófilos na fibrose que acompanha a miocardite e a inflamação da musculatura do tubo digestivo na doença de

\footnotetext{
Trabalho do Curso de Pós-Graduação em Patologia Humana da Faculdade de Medicina do Triângulo Mineiro, Uberaba, MG e do Departamento de Clínica Médica da Faculdade de Ciências da Saúde da Universidade de Brasília, Brasília, DF. Endereço para correspondência: Prof. Edmundo Chapadeiro, Depto. de Patologia, Medicina Legal e Deontologia Médica/ FMTM, Av. Getúlio Guaritá 130, 38025-050 Uberaba, MG. Recebido para publicação em $03 / 09 / 91$.
}

Chagas.

A finalidade deste trabalhoé investigar a presença e o papel dos mastócitos e granulócitos eosinófilos, na fibrose miocárdica, do rato chagásico crônico.

\section{MATERIAL E MÉTODOS}

Consta de corações de 40 ratos albinos Wistar, 30 na fase tardia (por volta de 8 meses) de infecção chagásica, produzida por via intraperitonial pelas cepas Y, São Felipe (12SF) e Colombiana (Col) do Trypanosoma cruzi e 10 não infectados (grupo controle). Os ratos infectados foram divididos em 3 grupos de 10 animais, inoculados com baixo, médio e alto inóculo correspondendo, respectivamente a 2000-3000, 4000-5000 e 6000 parasitas/g de peso corporal. Foi a seguinte a distribuição dos animais segundo a cepa e a intensidade do inóculo:

\begin{tabular}{lccc}
\hline Inóculo & Cepa Y & Cepa 12SF & Cepa Col \\
\hline baixo & 3 & 3 & 3 \\
médio & 5 & 4 & 7 \\
alto & 2 & 3 & - \\
\hline Total de animais & 10 & 10 & 10 \\
\hline
\end{tabular}

Os animais do grupo controle possuíam as mesmas características quanto à raça, sexo, idade e 
Pinheiro MCN, Beraldo PSS, Junqueira Júnior LF, Lopes ER, Chapadeiro E. Análise quantitativa de mastócitos e de granulócitos eosinófilos no miocárdio de ratos Wistar cronicamente infectados pelo Trypanosoma cruzi. Contribuição ao conhecimento da fibrose miocárdica. Revista da Sociedade Brasileira de Medicina Tropical 25:45-50, jan-mar, 1992.

peso dos infectados. Tanto os ratos controles como os infectados foram sacrificados na mesma época.

O coração de cada animal foi retirado durante a necrópsia, e após análise macroscópica, cortando em duas metades; a seguir o material foi fixado em formol neutro a $10 \%$ e incluído em parafina. De cada bloco foram obtidos quatro cortes de $5-7 \mu \mathrm{m}$ de espessura, próximos entre si, que foram corados pela hematoxilina-eosina (para análise do comprometimento geral do miocárdio), pelo Giemsa modificado para tecido (visando a identificação e contagem de mastócitos e de eosinófilos) e pelos métodos de Azan-Heidenhain e Sirius-red (para estudo da fibrose).

A contagem das células e a análise da fibrose foram realizadas em 10 campos microscópicos consecutivos de $200 \mathrm{X}$ na parede livre do terço médio do ventrículo esquerdo de cada corte, correspondendo a uma área de $8 \mathrm{~mm}^{2}$.

Os dados numéricos foram submetidos à análise estatística através dos testes do qui-quadrado, MannWhitney e pela estatística de Kruskal-Wallis ${ }^{7}$. Para fins de conclusão, em termos estatísticos, adotou-se o nível de significância de 0,05 .

\section{RESULTADOS}

Dos 30 animais infectados, $26(86,66 \%)$ apresentaram miocardite crônica (Figuras 1 e 2) caracterizada por infiltrado de células mononucleares (macrófagose linfócitos) e fenômenos degenerativonecróticos das fibrocélulas; fibrose ocorreu apenas em $12 \operatorname{dos} 26$ animais com miocardite e foi identificada como áreas irregulares de neoformação conjuntiva localizada no endo e perimisio, coradas em azul pelo método de Azan-Heidenhain e birrefringentes, alaranjadas, nas preparações coradas pelo Sirius-red, observadas à polarização. Três animais infectados com os diferentes inóculos da cepa $12 S F$ e um com baixo inóculo da cepa $Y$ não desenvolveram miocardite. Consideraram-se três tipos de fibroses: 1 . focal, quando a área ou a soma das áreas coradas em azul alcançava até $25 \%$ do campo examinado (Figura 3); 2. zonal, quando a soma dessas áreas compreendia 25 a $50 \%$ (Figura 4) do campo miocárdico; 3. difusa, quando as áreas coradas em azul ultrapassavam $50 \%$ dos campos examinados (Figura 5).
Conforme indicado na Tabela 1 , o número médio de mastócitos encontrado no miocárdio dos grupos de animais infectados com diferentes cepas do Trypanosoma cruzi, foi significativamente maior ( 3 a 5 vezes) que no grupo controle (Figuras 6A e B). Comparando-se as médias nos três grupos infectados entre si, através da estatística de KruskalWallis ( $\mathrm{H}=3,682 ; \mathrm{gl}=2 ; \mathrm{p}=0,158638)$, não se pode rejeitar a hipótese de igualdade; contudo não se deve deixar de lado a magnitude do poder estatístico desta decisão (erro $\beta>90 \%$ ), devido ao pequeno número de observações.

Tabela 1 - Média e desvio-padrão do número de mastócitos no miocárdio ventricular esquerdo dos ratos, segundo as cepas de T. cruzi.

\begin{tabular}{ccc}
\hline Grupos & Média & Desvio-padrão \\
\hline Controle & 6,50 & 4,04 \\
Y & 21,00 & 11,57 \\
$12 \mathrm{SF}$ & 18,90 & 7,91 \\
COL & 29,10 & 14,08 \\
\hline
\end{tabular}

Estatística de Kruskal-Wallis $=21,196 \quad p=0,00096$

Entre os corações estudados, a fibrose ocorreu em $12(40 \%)$ dos ratos infectados e em $10 \%$ dos controles, como indica a Tabela 2. Na Tabela 3,

Tabela 2 - Fibrose no miocárdio ventricular esquerdo de ratos controles e infectados pelo $\mathrm{T}$. cruzi.

\begin{tabular}{|c|c|c|c|c|c|c|}
\hline \multirow{3}{*}{ Grupos } & \multicolumn{6}{|c|}{ Fibrose } \\
\hline & \multicolumn{2}{|c|}{ Sim } & \multicolumn{2}{|c|}{ Não } & \multicolumn{2}{|c|}{ Total } \\
\hline & $\mathrm{N}^{\circ}$ & $\%$ & $\mathrm{~N}^{\circ}$ & $\%$ & $\mathrm{~N}^{\circ}$ & $\%$ \\
\hline Controle & 1 & 10,0 & 9 & 90,0 & 10 & 100,0 \\
\hline Chagásico & 12 & 40,0 & 18 & 60,0 & 30 & 100,0 \\
\hline Total & 13 & 32,5 & 27 & 67,5 & 40 & 100,0 \\
\hline$-3,00$ & & & & & & \\
\hline
\end{tabular}


Pinheiro MCN, Beraldo PSS, Junqueira Júnior LF, Lopes ER, Chapadeiro E. Análise quantitativa de mastócitos e de granulócitos eosinófilos no miocárdio de ratos Wistar cronicamente infectados pelo Trypanosoma cruzi. Contribuição ao conhecimento da fibrose miocárdica. Revista da Sociedade Brasileira de Medicina Tropical 25:45-50, jan-mar, 1992.
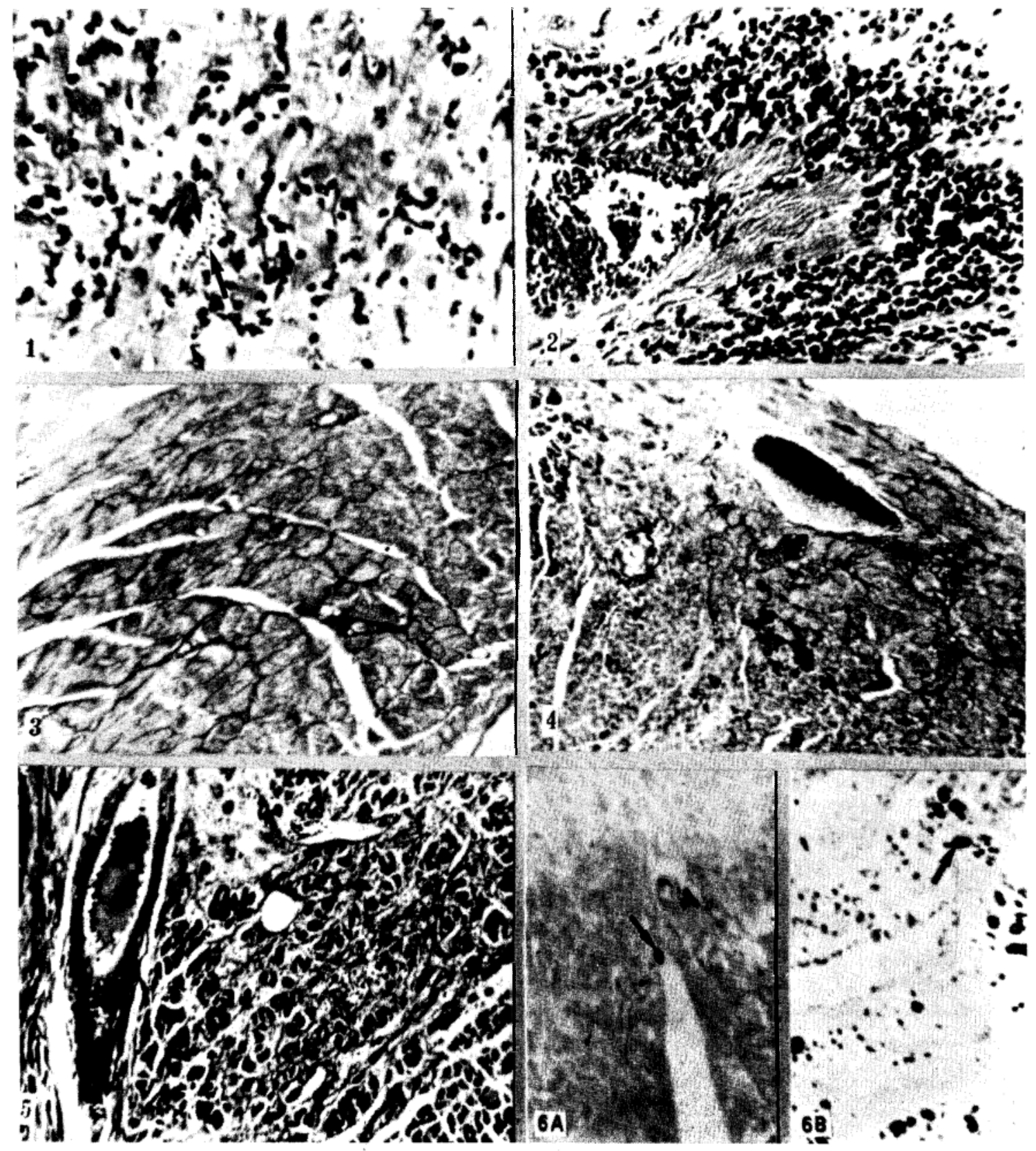

Figura 1 - Rato chagásico. Miocardite crônica com ninho de amastigotas do $\mathrm{T}$. cruzi (seta) no interior de miocélulas. $H E 400 x$.

Figura 2 - Rato chagásico. Miocardite crônica fibrosante com intenso infiltrado mononuclear. HE 400x.

Figura 3 - Rato chagásico. Miocardite crônica com fibrose focal. Tricrômico de Heidenhain 100x.

Figura 4 - Rato chagásico. Miocardite crônica com fibrose zonal. Tricrômico de Heidenhain 100x.

Figura 5 - Rato chagásico. Miocardite crônica com área de fibrose difusa. Tricômico de Heidenhain 100x.

Figuras $6 A$ e $6 B$ - Mastócitos (setas) no miocárdio de ratos não chagásico (6A) e chagásico crônico (6B). Observar a diferença entre o número de mastócitos nos dois animais. Giemsa $400 x$. 
Pinheiro MCN, Beraldo PSS, Junqueira Jünior LF, Lopes ER, Chapadeiro E. Análise quantitativa de mastócitos e de granulócitos eosinófilos no miocárdio de ratos Wistar cronicamente infectados pelo Trypanosoma cruzi. Contribuição ao conhecimento da fibrose miocárdica. Revista da Sociedade Brasileira de Medicina Tropical 25:45-50, jan-mar, 1992.

Tabela 3 - Disiribuição da fibrose, em doze ratos, de acordo com a cepa e a intensidade do inóculo.

\begin{tabular}{|c|c|c|c|c|c|c|c|}
\hline \multirow{3}{*}{ Inóculo } & \multicolumn{6}{|c|}{ Cepas } & \multirow{3}{*}{$\begin{array}{l}\text { Númerc } \\
\text { Total }\end{array}$} \\
\hline & \multicolumn{2}{|r|}{$Y$} & \multicolumn{2}{|c|}{$12-\mathrm{SF}$} & \multicolumn{2}{|c|}{$\mathrm{COL}$} & \\
\hline & $\mathrm{N}^{\circ}$ & $\%$ & $N^{0}$ & $\%$ & $\mathrm{~N}^{\circ}$ & $\%$ & \\
\hline Médio & 4 & 66,66 & 1 & 50,00 & 4 & 100,00 & 9 \\
\hline Alto & 2 & 33,33 & 1 & 50,00 & - & - & 3 \\
\hline Total & 6 & 100,00 & 2 & 100,00 & 4 & 100,00 & 12 \\
\hline
\end{tabular}

constata-se que os 12 animais que apresentaram fibrose receberam alto e médio inóculo e que 6 deles haviam sido inoculados com a cepa $Y, 2$ com a $12 \mathrm{SF}$ e 4 com a Col. Em nenhum rato infectado com baixo inóculo desenvolveu-se fibrose miocárdica.

A Tabela 4, mostra que a média e o desviopadrão do número de mastócitos nos animais infectados que apresentaram fibrose foram próximos daqueles sem fibrose. De acordo com o teste de Mann-Whitney $=0,004 \mathrm{p}=0,9427$, não houve diferença significativa entre essas médias.

\section{Tabela 4 - Média e desvio padrão do número de mastócitos nos animais infectados com e sem fibrose miocárdica.}

\begin{tabular}{ccc}
\hline Fibrose & Média & Desvio-padrão \\
\hline Sim & 22,33 & 11,21 \\
Não & 22,88 & 12,55 \\
\hline
\end{tabular}

Estatística de Mann-Whitney $=0,004 \quad \mathrm{p}=0,9427$

A pesquisa dos eosinófilos revelou-se negativa no miocárdio dos dez corações controles e positiva em sete dos trinta corações dos animais infectados. Nestes últimos, o número de células variou de 1 a 4. Os dados não permitem análise estatística.

\section{DISCUSSÃO}

Nossas observações sugerem que o aumento do número dos mastócitos no miocárdio dos ratos chagásicos por nós estudados, está associado fundamentalmente à infecção pelo Trypanosoma cruzi e não à miocardite crônica fibrosante. A técnica histológica que empregamos não identifica mastócitos degranulados, mas é válida para casos em que se constata aumento do número destas células.

Pelo fato de não termos observado relação entre a fibrose miocárdica e o aumento do número de mastócitos poder-se-ia questionar se o aumento do número destas células é realmente um dos fatores responsáveis pelo caráter fibrosante da lesão miocárdica e pela fibrose das musculares do esôfago e/ou intestino no homem, como alguns sugerem 21 25. Deve-se, entretanto, realçar a diversidade das condições humanas e experimentais e a existência de outras variáveis (como por exemplo tipos de cepas, intensidade do inóculo, etc.) entre os diversos trabalhos citados.

Dos animais infectados, $40 \%$ desenvolveram fibrose miocárdica e é importante realçar que esta só foi constatada nos animais infectados com médio e alto inóculos, não ocorrendo em nenhum dos nove que receberam baixo inóculo, independentemente da cepa inoculada. Por outro lado, $60 \%$ dos animais infectados com a cepa $Y$ desenvolveram fibrose, a qual ocorreu em somente $40 \%$ dos ratos infectados com a cepa Col e em $20 \%$ daqueles inoculados com a cepa $12 \mathrm{SF}$. Diante do pequeno número de casos, não foi possível análise estatística. Entretanto, os dados dispostos na Tabela 3 sugerem que a maioria dos casos com fibrose está relacionada ao inóculo médio e à cepa $Y$. Não temos elementos para explicar a fibrose miocárdica observada em um dos animais controle.

Aumento do número de mastócitos na 
Pinheiro MCN, Beraldo PSS, Junqueira Júnior LF, Lopes ER, Chapadeiro E. Análise quantitativa de mastócitos e de granulócitos eosinófilos no miocárdio de ratos Wistar cronicamente infectados pelo Trypanosoma cruzi. Contribuição ao conhecimento da fibrose miocárdica. Revista da Sociedade Brasileira de Medicina Tropical 25:45-50, jan-mar, 1992.

tripanossomíase cruzi foi relatado em modelos experimentais em outras sedes que não o miocárdio. Menezes e Alcântara ${ }^{12}$ descreveram nas áreas de reinoculação, na pele de camundongos, maior quantidade de mastócitos e admitem ser a inflamação produzida pelo inóculo a responsável pelo fenômeno. Trabalhando com camundongos, cronicamente infectados com a cepa "ABC" do Trypanosoma cruzi, Tafurie Brener ${ }^{23}$ também constataram intenso aumento do número de mastócitos, especialmente na muscular do intestino. Tafuri e Raso ${ }^{25}$, confirmaram ocorrer mastocitose na doença de Chagas experimental e lançaram a hipótese de que estaria relacionada com a gênese da fibrilopoiese. Entretanto, na fase aguda da infecção de ratos Wistar, inoculados com as mesmas cepas do Trypanosoma cruzi por nós utilizadas no presente estudo, Chapadeiro e cols ${ }^{5}$ se referem à falta ou escassez de mastócitos, em contraste com sua abundância nos animais controles.

Com relação aos granulócitos eosinófilos no miocárdio não nos foi possível tirar conclusões, tendo em vista o número pouco expressivo daquelas células nos ratos chagásicos e de não terem sido detectadas nos controles.

Em conclusão, são necessárias novas investigações para procurar esclarecer o papel dos mastócitos e dos eosinófilos na gênese da fibrose miocárdica da doença de Chagas, entre outras razões, pelo fato de que nas inflamações em geral, tem-se atribuído aos mastócitos ${ }^{3} 618 \quad 20$ e ao granulócitos eosinófilos ${ }^{19}$ participação na colanogênese do fenômeno produtivo reparativo.

\section{SUMMARY}

We did mast cell and eosinophil granulocyte counts in the myocardium of forty chronic chagasic Wistar albino rats. We used 10 controls rats and 30 animals with late stage $\left(8^{\text {th }}\right.$ month) infection of São Felipe, $Y$ and Colombian Trypanosoma cruzi strains, with variable degree of chronic myocarditis. We found chronicfibrosing myocarditis (fibrosis) in $40 \%$ of the infected animals. It was detected increased mast cell count in the chagasic rats associated with infection and not related with myocardial fibrosis. There was no increase in the eosinophil counts.

Key-words: Chagas'disease. Myocardial fibrosis. Mast cell. Eosinophil granulocyte.

\section{AGRADECIMENTOS}

Ao Prof. Euclides Ayres de Castilho e Raimundo Camurça de Menezes pela orientação e execução da análise estatística.

\section{REFERÊNCIAS BIBLIOGRÁFICAS}

1. Adad SJ. Contribuição ao estudo da anatomia patológica e da patogênese do megaesôfago chagásico. Tese de Mestrado, Faculdade de Medicina do Triângulo Mineiro, Uberaba, 1989.

2. Almeida HO, Pereira FEL, Tafuri WL. Estudo quantitativo dos mastócitos na cardiopatia chagásica crônica. Revista do Instituto de Medicina Tropical de São Paulo 17:5-9, 1975.

3. Bensley SH. Histological studies of the reactions of cells and intercelular substances of loose connective tissue to the spreading factor of testicular extracts. Annals of the New York Academy of Sciences 51:893-898, 1949.

4. Bogliolo L. As causas anatômicas da insuficiência cardíaca na cardiopatia (miocardite) chagásica crônica, estudadas comparativamente com as causas anatômicas da insuficiência cardíaca noutras cardiopatias. Parte II. Arquivos Brasileiros de Cardiologia 29:479-483, 1976.

5. Chapadeiro E, Beraldo PSS, Jesus PC, Oliveira Jr WP, Junqueira Jr LF. Lesões cardíacas em ratos Wistar inoculados com diferentes cepas do Trypanosoma cruzi. Revista da Sociedade Brasileira de Medicina Tropical 21:95-103, 1988.

6. Fernex M. Contribution a l'étude physio-patologique des mastocytes dans le myocarde. Actualité Cardiologie et Angiologie 9:269, 1960.

7. Hollander M, Wolfe DA. Nonparametric statistical methods. John Wiley \& Sons, New York, 1973.

8. Laranja FS, Dias E, Nóbrega G, Miranda A. Chagas'disease. A clinical, epidemiologic and pathologic study. Circulation 14:1035-1060, 1956. 
Pinheiro MCN, Beraldo PSS, Junqueira Júnior LF, Lopes ER, Chapadeiro E. Análise quantitativa de mastócitos e de granulócitos eosinófilos no miocárdio de ratos Wistar cronicamente infectados pelo Trypanosoma cruzi. Contribuição ao conhecimento da fibrose miocárdica. Revista da Sociedade Brasileira de Medicina Tropical 25:45-50, jan-mar, 1992.

9. Lopes ER, Chapadeiro E, Tafuri WL, Prata AR. Patologia das principais doenças tropicais no Brasil In: Lopes ER, Chapadeiro E, Raso P, Tafuri WL (ed) Bogliolo Patologia, $4^{\mathrm{a}}$ edição, Guanabara Koogan, Rio de Janeiro p.1047-1120, 1987.

10. Lorenzana R. Chronic Chagasic myocarditis. Report of a case. American Journal of Clinical Pathology 48:39-43, 1967.

11. Mazza S, Jörg ME, Feijoo EJC. Primer caso crônico de forma cardíaca de enfermidad de Chagas demonstrado en Santiago del Estero. Publicación de la Mision de Estudios de Patologia Regional Argentina 38:1-75, 1938.

12. Menezes H, Alcantara FG. Os mastócitos da pele de camundongos infectados experimentalmente com Trypanosoma cruzi. O Hospital 68:187-190, 1965.

13. Mignone C. Alguns aspectos da anatomia patológica da cardite chagásica crônica. Tese de Professor Catedrático, Universidade de São Paulo, São Paulo, 1958.

14. Molina HA, Kierszenbaum F. A study of human myocardial tissue in Chagas'disease: Distribution and frequency of inflammatory cell types. International Journal of Parasitology 17:1297-1300, 1987.

15. Molina HA, Kicrszenbaum F. Immunohistochemical detection of deposits of eosinophil-derived neurotoxin and eosinophil peroxidase in the myocardium of patients with Chagas'disease. Immunology 64:725-731, 1988.

16. Molina HA, Kierszenbaum F. Interaction of human cosinophils or neutrophils with Trypanosoma cruzi in vitro causes bystander cardiac cell damage. Immunology 66:289-295, 1989.

17. Molina HA, Kierszenbaum F. Eosinophil activation in acute and chronic myocardial lesions and deposition of toxin eosinophil granule proteins on heart myofibers. Journal of Parasitology 75:129$133,1989$.

18. Morrione TG. The formation of collagen fibres by the action of heparin an soluble collagen. An electron microscope study. Journal of Experimental Medicine 96:107-116, 1952.

19. Olsen EGJ, Spray CJF. The pathophysiology of endomyocardial fibrosis. Arquivos Brasileiros de Cardiologia 38:319-323, 1982.

20. Orfanos C, Sturttgen G. Das zerfallastadium un die folgen der mastzelledegamullerung mit besonderer beruckschtigeng der mesenchymalen reaktion. Zeitschrift fur Zellforschung und Mikroskopische Anatomie 61:622-632, 1963.

21. Pereira FEL. Estudo quantitativo dos mastócitos na musculatura do esôfago de chagásicos crônicos. Revista do Instituto de Medicina Tropical de São Paulo 14:30-32, 1972.

22. Romaña C. Enfermedad de Chagas. Lopes Libreros, Buenos Aires, 1963.

23. Tafuri WL, Brener Z. Lesões dos plexos de Meissner e de Auerbach do intestino do camundongo albino na fase crônica da tripanossomíase cruzi experimental. Revista do Instituto de Medicina Tropical de São Paulo 9:149-154, 1967.

24. Tafuri WL, Lopes ER, Chapadeiro E, Miziara HL, Santos BG, Raso P. Miocardite chagásica aguda humana: Provável agressão à célula cardíaca pelo granulócito eosinófilo. Revista da Sociedade Brasileira de Medicina Tropical 16:122-124, 1983.

25. Tafuri WL, Raso P. Anatomia Patológica. In: Raia AA. (ed) Manifestações digestivas da moléstia de Chagas. $1^{\mathrm{a}}$ edição. Savier, São Paulo p.60-79, 1983. 